\title{
> Filosofia negativa, filosofia positiva: a crítica de Schelling ao idealismo
}

\author{
> Negative philosophy, positive philosophy: \\ Schelling's critique to idealism
}

\section{por Wagner Félix}

Professor Associado do Departamento de Filosofia da Universidade Estadual de Maringá (UEM) e docente permanente do Programa de Pós-Graduação em Filosofia da UEM (PGF-UEM), Doutor em Filosofia pela Universidade Federal do Rio de Janeiro (UFRJ).E-mail: wdcfelix@uem.br. ORCID: 0000-0002-8229-4211.

\section{Resumo}

O propósito deste artigo é a exposição de momentos chave da crítica schellingiana à filosofia idealista como forma de compreender o estatuto da filosofia positiva buscada por Schelling em sua obra madura. A crítica de Schelling, dirigida aos resultados negativos da filosofia formal de seus contemporâneos, é contraposta à busca pela positividade na natureza, na mitologia, na história, na religião, em vista da "natureza extralógica da existência", que se rebela contra a conformação da totalidade do que pode ser conhecido a uma ordem necessária. Embora o projeto da filosofia positiva seja elaborado a partir da década de 1820, já em suas primeiras obras encontramos elementos de sua crítica à pretensão de subsumir em um sistema filosófico a totalidade da realidade.

Palavras-chave: Schelling. Idealismo alemão. Filosofia positiva. Sistema da filosofia.

\begin{abstract}
The purpose of this article is to discuss key moments of Schelling's criticism to idealist philosophy and as a way of understanding the status of the positive philosophy he sought in his mature work. Schelling's criticizes the negative results of the formal philosophy of his contemporaries. against which he counters with the search for positivity in nature, mythology, history, and religion, with respect to the "extralogical nature of existence", which rebels against the project of conforming the totality of what can be known to a necessary order. Although Schelling's project of a positive philosophy began in the 1820 s, his earlier works show clear elements of his position against the pretension of subsuming the totality of reality into a philosophical system.

Keywords: Schelling. German Idealism. Positive philosophy. System of philosophy.
\end{abstract}


$\mathrm{Na}$ história da recepção de Schelling no séc. XX, sua obra é tradicionalmente lida como ponto intermediário entre a filosofia de Fichte e Hegel. A despeito da reconhecida aliança entre paixão romântica e o rigor intelectual de seus escritos, afirmou-se frequentemente que Schelling não teria tido sucesso em seu projeto filosófico - opinião compartilhada, por exemplo, por Karl Jaspers, que de outra forma reconheceu a importância da chamada filosofia positiva de Schelling em trazer para o centro da discussão filosófica a questão da existência. Essa discussão se contrapunha à preocupação com a essência ou a ideia, característica da "filosofia negativa", que Schelling nomeou e reconheceu em Fichte, Hegel e em suas próprias obras de juventude. Nas preleções sobre a Fundação da Filosofia Positiva, Schelling afirma que

Em todos os seus aspectos, o mundo parece ser muito menos um produto da razão pura. Ele contém em si uma massa tão preponderante daquilo que não é razão, que quase se poderia dizer que o que é racional é o que é acidental. ${ }^{1}$

A partir da década de 1820, Schelling desenvolve explicitamente a crítica ao idealismo pós-kantiano, que se tornará explícita em suas preleções das décadas de 1830 e 1840, em Munique e Berlim. Sua crítica dirige-se ao que ele identifica com os resultados negativos da filosofia crítica e formal que se tornou exigência da modernidade, e à qual ele passa a contrapor a busca por uma positividade na mitologia, na história, na religião, levando em conta a "natureza

\footnotetext{
1 "Die Welt sieht nach alles weniger aus als nach einem Erzeugnis reiner Vernunft. Sie enthält eine überwiegende Masse von Unvernunft, sodass man beinahe sagen könnte, das Rationale sei [nur] das Accidens." Friedrich Wilhelm Joseph von Schelling, Grundlegung der Positiven Philosophie: Münchener Vorlesung WS 1832/33 und SS 1833, 1972, p. 100, tradução nossa.
} 
extralógica da existência", que se rebela contra o projeto de conformá-la a uma ordem ditada pela necessidade. Diante desse quadro, nosso simples propósito é a exposição da crítica schellingiana, colocando em questão, também, o estatuto da filosofia positiva buscada por Schelling como precursora de um pensamento contemporâneo que não tem escolha, se não iniciar de uma positividade dada, qual seja, o fato da existência concreta. Trata-se, para Schelling, de uma tarefa presente já em seus primeiros escritos, a de reconhecer que o próprio pensamento se subordina a algo que lhe é prévio, de tal modo que o pensamento não pode pretender conter em si a própria positividade. Schelling nega que o possível sistema do conhecimento possa ser ao mesmo tempo o sistema da totalidade do real, ou seja, que o pensamento possa, de algum modo, conter em si o absoluto ou incondicionado.

A recusa de Schelling em assumir como ponto de partida um método necessário para a construção de um sistema filosófico é uma marca de suas diversas tentativas de, justamente, expor o caráter sistemático da filosofia. Esse caráter, no entanto, é compreendido no sentido da inexorável dignidade do pensamento como atividade da liberdade, e não como produto da reflexão deliberada. Esta tensão informa seu exame da filosofia moral, da natureza, da arte, do conhecimento; é seu caráter, de fato, que o sistema da filosofia não toma a forma de um discurso logicamente coerente, mas é uma forma da ação e do desejo.

Uma vez que toda nossa filosofia procede do ponto de vista da intuição, e não daquele da reflexão, com que se ocupa, por exemplo, por Kant e sua filosofia, nós deveremos derivar a série de atos agora incipientes da inteligência enquanto atos, e não, diga-se, enquanto conceitos de atos, ou 
como categorias. Pois como esses atos chegam à reflexão é o problema para uma época posterior da auto-consciência. ${ }^{2}$

A singularidade de Schelling em relação à filosofia kantiana reside em sua decisão de que, para que um sistema filosófico tivesse sentido, deveria ser fundado no que é imediatamente absoluto, exigência que a construção do sistema por meio da reflexão não é capaz de cumprir. Para o pensador, contudo, isso não significaria um retorno à filosofia dogmática pré-kantiana, mas deverse-ia realizar desde o impulso da filosofia crítica. ${ }^{3}$ A filosofia kantiana teve uma repercussão imediata e influência decisiva nos projetos filosóficos que se seguiram, de forma que toda tentativa subsequente de tratar das questões filosóficas fundamentais não pode escapar de lidar, de uma forma ou de outra, com os limites da razão, tais como esclarecidos pela crítica kantiana. Em outras palavras, seria o reconhecimento da impossibilidade de conhecer as coisas tais

\footnotetext{
2 "Da unsere ganze Philosophie auf dem Standpunkt der Anschauung, nicht auf dem der Reflexion steht, auf welchem z.B. Kant mit seiner Philosophie befindlich ist, so werden wir auch die jetzt beginnende Reihe von Handlungen der Intelligenz als Handlungen, nicht etwa als Begriffe von Handlungen, oder als Kategorien ableiten. Denn wie jene Handlungen zur Reflexion gelangen, ist die Aufgabe einer späteren Epoche des Selbstbewußtseyns." Friedrich Wilhelm Joseph von Schelling, System des transzendentalen Idealismus, 1995, p. 524 [SW I/3, 456], tradução nossa.

${ }^{3}$ Segundo Andrew Bowie, "Para Schelling, como Jacobi e Hölderlin, é claro que o Absoluto não pode aparecer como ele mesmo, precisamente porque não pode se tornar um objeto. [...] A questão é simplesmente o problema da reflexividade ou autorreferência, que é o problema central da filosofia romântica, e que Hegel pensou ter resolvido. Novalis diz em uma formulação clássica, nos chamados Estudos de Fichte de 1795-6: 'A essência da identidade só pode ser estabelecida em uma proposição aparente (Scheinsatz). Deixamos o idêntico para poder representá-lo'. Por isso, ele quer dizer que, ao tentar dizer que algo é o mesmo que outra coisa, temos que dividir o que é o mesmo para mostrar que é o mesmo, como na proposição $\mathrm{A}=\mathrm{A}$, onde os dois são diferentes. $\mathrm{Cf}$. Andrew Bowie, Schelling and Modern European Philosophy: An Introduction, 1993, p. 49, tradução nossa.
} 
como elas são, independentes de nós ou independentes de como são para nós, sem abrir mão, no entanto, da possibilidade mesma do conhecimento.

\section{Segundo Kant,}

Sob o domínio da razão não devem nossos conhecimentos em geral formar uma rapsódia, mas um sistema, e somente deste modo podem apoiar e fomentar os fins essenciais da razão. Ora, por sistema, entendo a unidade de conhecimentos diversos sob uma ideia. Esta é o conceito racional da forma de um todo, na medida em que nele se determinam a priori, tanto o âmbito do diverso, como o lugar respectivo das partes. $O$ conceito científico da razão contém assim o fim e a forma do todo que é correspondente a tal fim. A unidade do fim a que se reportam todas as partes, ao mesmo tempo que se reportam umas às outras na ideia desse fim, faz com que cada parte não possa faltar no conhecimento das restantes e que não possa ter lugar nenhuma adição acidental, ou nenhuma grandeza indeterminada da perfeição, que não tenha seus limites determinados a priori. O todo é, portanto, um sistema organizado (articulado) e não um conjunto desordenado (coarcevatio); pode crescer internamente (per intussusceptionem), mas não externamente (per oppositionem), tal como o corpo de um animal, cujo crescimento não acrescenta nenhum membro, mas, sem alterar a proporção, torna cada um deles mais forte e mais apropriado aos seus fins. ${ }^{4}$

Contudo, embora Kant explicitamente conceba a ideia de sistema como uma unidade intrínseca, os pensadores subsequentes persistentemente criticaram Kant por ter separado a razão entre os domínios da teoria e da prática, do dever e da inclinação, da lei e da autodeterminação, os quais são irredutíveis uns aos outros. Sendo assim não estão reunidos sob um único sistema. Kant introduz na filosofia um dualismo que admite tanto a causalidade empírica como a causalidade livre da vontade. Quanto à primeira, seria o domínio da

\footnotetext{
${ }^{4}$ Immanuel Kant, Crítica da razão pura, 1994, B860.
} 
concatenação dos fenômenos no tempo, âmbito no qual é possível o conhecimento dos objetos da experiência, ou seja, o domínio teórico. Quanto à outra, seria o domínio da moral ou da prática. Uma consequência desse dualismo, para Kant, é que aquilo que pertence ao domínio prático são as ideias da razão, as quais posso pensar, e, no entanto, não posso conhecer. Deus, imortalidade da alma, liberdade, devem, de fato, ser ainda pensadas no domínio prática da razão, porém não tem qualquer realidade objetiva.

De fato, pensadores como Fichte, Schelling, Hegel, e também Schulze, Reinhold, Jacobi e outros, passam a compreender a crítica da razão empreendida por Kant não como o sistema do conhecimento tal como ele pode ou deve ser, mas como uma propedêutica a esse sistema. Assim, resta ainda a tarefa de investigar a possibilidade de se estabelecer um fundamento último do sistema da razão humana positivamente, sem cair novamente no ceticismo ou no dogmatismo. Isso significa, em última instância, ter de pensar na possibilidade de um fundamento último do conhecimento que não seja independente de nós. Consequentemente, também será preciso pensar na possibilidade de nós - ou melhor, do âmbito do "eu penso" - podermos de fato alcançar toda a realidade, e legitimamente fundar um sistema da razão segundo sua ideia necessária.

Schelling está desde seus primeiros escritos envolto com as consequências das diversas interpretações da crítica kantiana. Logo nas Cartas filosóficas sobre o Dogmatismo e o Criticismo, de 1795, que escreveu aos 19 anos, Schelling se confronta com os intérpretes da filosofia kantiana que, mesmo admitindo os limites impostos ao uso teórico da razão no que diz respeito à fundamentação do sistema da filosofia, abusam de seu uso prático ao pressupor a existência de um 
Deus moral. No que tange às vontades desse Deus, elas se dariam conforme a lei moral que encontramos para regular nossa própria liberdade. A solução de Schelling para esse problema é a de admitir a possibilidade de uma intuição intelectual, ou seja, a faculdade de poder ver, de ter presente (sem ser por intermédio da intuição sensível, o único tipo de intuição admitido por Kant) a unidade do universal e do particular, do infinito e do finito, da identidade e da diferença, ou seja, aquilo que, na filosofia pós-kantiana, é designado por absoluto.

Schelling, ao longo das Cartas, irá argumentar que, em verdade, do ponto de vista especulativo, não parece ser possível uma solução satisfatória que resolva para nós o problema de qual sistema tem mais razão. Isso se deve porque, em última instância, não será exclusivamente pela via da razão que o problema prático será resolvido, mas somente pela prática.

O fundamento que me leva a afirmar que esses dois sistemas inteiramente opostos entre si, o dogmatismo e o criticismo, são igualmente possíveis, e que ambos subsistirão um ao lado do outro enquanto todos os seres finitos não tiverem atingido o mesmo grau de liberdade, é, concisamente, o seguinte: os dois sistemas têm o mesmo problema, e esse problema absolutamente não pode ser solucionado teoricamente, mas apenas praticamente, isto é, por liberdade. Ora, só são possíveis duas soluções desse problema: uma delas leva ao criticismo, a outra ao dogmatismo. Qual das duas escolhemos, depende da liberdade de espírito que conquistamos para nós mesmos. Temos de ser aquilo que pretendemos professar teoricamente; mas nada nos pode convencer de que o somos, a não ser o próprio esforço que fazemos para sê-lo. Esse esforço realiza nosso saber diante de nós mesmos; e este se torna, justamente por isso, puro produto de nossa liberdade. Temos de ter trabalhado para alcançar o ponto 
de que queremos partir: nenhum homem pode alcançar este ponto por silogismos, nem pode deixar-se conduzir por silogismos de outrem. ${ }^{5}$

Nesta passagem, Schelling ainda critica os argumentos comumente utilizados em torno da polêmica do dogmatismo e do criticismo. Porém, logo na Oitava Carta, sua questão se revelará como o problema dos limites para uma possível construção de um sistema da filosofia, seja segundo o criticismo, seja segundo o dogmatismo, naquilo que para ele é o único começo possível do sistema enquanto realização da liberdade humana.

Com efeito, em todos nós reside uma faculdade secreta, maravilhosa, de retirar-nos da mudança do tempo para nosso íntimo, para nosso eu despido de tudo aquilo que vem de fora, e, ali, na forma da imutabilidade, intuir o eterno em nós. Essa intuição é a experiência mais íntima, mais própria, e unicamente dela depende tudo aquilo que sabemos e cremos de um mundo supra-sensível. Essa intuição, em primeiro lugar, nos convence de que algo é, em sentido próprio, enquanto todo o restante, ao qual transferimos essa palavra, apenas aparece. Ela se distingue de toda intuição sensível por ser produzida somente por liberdade, e é alheia e desconhecida a todos os outros, cuja liberdade, sobrepujada pela potência impositiva do objeto, mal basta para a produção da consciência. Contudo, mesmo para aqueles que não possuem essa liberdade da intuição de si, há pelo menos uma aproximação dela, experiências mediatas pelas quais ela deixa pressentir sua existência. ${ }^{6}$

Esta intuição é chamada por Schelling de intuição intelectual. É a intuição do absoluto enquanto intuição do Mesmo, isto é, da pura indiferença entre o eu que intui e o eu intuído, e que por isso não é reflexão, quer dizer, não é um voltar-

\footnotetext{
${ }^{5}$ Friedrich Wilhelm Joseph von Schelling, "Cartas filosóficas sobre o dogmatismo e o criticismo", 1989, p. 18.

${ }^{6}$ Ibidem, p. 24.
} 
se a si mesmo desde um saber de si, que primeiro toma o eu como objeto de um saber. Uma vez que o "eu" é tomado como objeto, ele é o "eu" de uma ação particular. A partir disso, por meio da abstração, seria possível retornar para o eu universal tomado como agente livre de toda ação. Contudo, esta espécie de saber é sempre mediada, e como tal, sujeita à causalidade objetiva, ou ao menos à suspeita de que aquilo que foi identificado como uma ação livre pudesse ter causas necessárias que não podemos conhecer. O que Schelling chama de intuição intelectual é, portanto, não o saber de um sujeito enquanto agente livre de uma ação, ou então a mera crença de que sou livre, mas a experiência imediata da liberdade: da produção, através da liberdade, da própria consciência de que sou livre. A realização prática do sistema, para Schelling, não significará a "atividade filosófica" do indivíduo, a realização dos seus desejos, de seus gostos. Embora Schelling, em certo momento, mais tarde, nas preleções sobre a Fundação da Filosofia Positiva da década de 1840, venha a se referir aos sistemas filosóficos como obras de ficção, romances históricos ou de formação, por serem, afinal, mero fruto da liberdade de seus criadores, isto valerá para o exercício da especulação, porém, não para o ser mesmo.

A constituição do ser, do Fundo e da Existência (Grund und Existenz) das coisas, tem uma história, que, para Schelling, não é posta em primeiro lugar pelo Eu em um ato efetivo de autoconsciência. Schelling afirmará que a consciência pode ser a primeira para si mesmo, mas não pode presumir ser a primeira em geral, isto é, o que primeiro põe em movimento o ser. Isto não significará, no entanto, que o homem, porque não é começo absoluto da determinação de seu próprio ser, está privado da liberdade, e encontra-se dominado pela causalidade da natureza. Como afirma F. Scott Scribner: 
O si mesmo torna-se consciente de ser condicionado por um estágio anterior de sua própria história, do qual ele não pode ser inteiramente consciente: ele encontra seu "fundamento em algo que não mais pode ser dado à consciência". Então aqui o que se encontra para sempre além da consciência, no entanto "intervém na presente fase da consciência". A influência do passado no presente é o que constitui o sentimento do tempo: "o sentimento de ser assim reconduzido para um estágio que, na realidade, não pode retornar para o sentimento do presente". ${ }^{7}$

A consciência não pode retornar a esse estágio, não pode sê-lo novamente, e assim, "agir", efetivar aquele ato agora em um nível "mais consciente" da consciência. A consciência torna-se consciente de seu limite temporal, ou melhor, na efetividade da temporalidade de seu vir a ser consciente de si, põe-se como limitada temporalmente. Ainda que condicionado em sua existência, o homem não deixa de ser livre, pois a liberdade não é entendida como uma faculdade mediante a qual exerce sua autodeterminação. O homem é livre, pois, em verdade, para Schelling, é o homem que é uma propriedade da liberdade: "a liberdade é a ordem mesma do ser e existe no homem porque ele lhe pertence e a manifesta de determinada forma" ${ }^{\text {. Por }}$ isso, desde o início, poderíamos argumentar, um sistema não poderá ser realizado especulativamente, conforme afirma Schelling nas Cartas filosóficas sobre o dogmatismo e o criticismo, mas apenas praticamente. É justamente através de maneira prática que o homem então realiza a ordem mesma do ser à medida que recupera para si a liberdade

\footnotetext{
7 "The self gradually becomes aware that its current situation is conditioned by an earlier one of which it can never be fully conscious: it finds its 'ground in something that no longer falls within consciousness'. So here what stands forever beyond consciousness nevertheless 'intervenes in the present phase of consciousness'. The influence of the past on the present is what constitutes the feeling of time: 'the feeling of thus being driven back to a stage that in reality cannot return to the feeling of the present'." F. Scott Scribner, "A Blasphemous Monologue", 2004, p. 150, tradução nossa.

${ }^{8}$ Carlos Morujão, "Introdução", 1993, p. 25.
} 
como o sentimento do fundo originário de onde provém, tendo se perdido na multiplicidade das coisas.

A crítica de Schelling aos limites de um projeto filosófico fundado na reflexão toma novamente como pano de fundo a questão moral em sua obra Investigações filosóficas sobre a essência da liberdade humana e os objetos com ela conexos, publicado por Schelling em 1809. Entre as Cartas e esse texto, Schelling, de modo algum, ignorou o problema da moralidade. Porém, nos escritos sobre a filosofia da Natureza, sobre a Filosofia Transcendental e mesmo sobre a arte, antes do problema da ação moral por excelência, está em jogo a compreensão da imediatez do ato do pensamento, ou seja, a compreensão da síntese absoluta. As Investigações colocam a liberdade no princípio do sistema, porém, de maneira muito mais explícita do que teria sido possível nas Cartas de 1795, a liberdade não pode ser compreendida primariamente como um ato da vontade; também a liberdade, podendo ser tomada como começo do pensamento, não será reflexiva.

As Investigações Filosóficas sobre a essência da liberdade humana e os objetos com ela conexos são consideradas uma ponte entre sua obra de juventude e seus escritos tardios, estes quase todos publicados postumamente, tendo sido desenvolvidos, em parte, em diversas séries de preleções ministradas por Schelling ao longo de várias décadas. O Freiheitschrifft, como é conhecido, avança o projeto schellingiano de fundar o sistema da filosofia na liberdade. Para o autor, isso significa fundá-lo no fato da liberdade, e não no ato especulativo da consciência, o que diz respeito, portanto, inicialmente não à possibilidade do conhecimento teórico de todas as coisas, porém, à liberdade humana e a relação do homem com o ser de todas as coisas. É fato conhecido - quase uma caricatura, 
em verdade - que a questão da liberdade é central para Schelling, dada a fama de seu Tratado. Liberdade, porém, não é apenas uma temática privilegiada no interior de um sistema que deve abarcar toda a realidade - mesmo se a liberdade for pensada como fundamento desse sistema. Antes de fundamento, em qualquer sentido lógico, a liberdade é o começo possível do pensamento, o limite desde o qual lidamos com o que de fato acontece, e não apenas com o que é e pode ser produzido pela razão, o que Schelling sublinha com a observação de que, porque o pensar não é uma ação, a lógica não pode ser o autor da história.

Não é arriscado dizer que Schelling, em nenhum momento, foi um defensor de uma filosofia sistemática que devesse dar conta absolutamente da realidade e que seguisse absolutamente um método necessário. Schelling, em verdade, desde cedo reconheceu a natureza multifacetada do fazer filosófico e sua irredutibilidade a um princípio lógico único - lembremos, o absoluto, para Schelling, não é dado numa proposição. Consideremos o que Schelling já afirmava em 1795, nas Cartas filosóficas sobre o dogmatismo e o criticismo:

Nada incomoda mais a cabeça filosófica do que quando ela ouve que, de agora em diante, toda filosofia deve permanecer presa nas algemas de um sistema. Nunca ela se sente maior do que quando vê diante de si a infinitude do conhecimento. A inteira dignidade de sua ciência consiste no fato de que ela nunca será completa. Naquele momento em que ela acreditaria ter completado seu sistema, ela tornar-se-ia insuportável para si mesma. Ela deixaria, nesse momento, de ser criadora, e se reduziria a ser um instrumento de sua criatura. ${ }^{9}$

\footnotetext{
${ }^{9}$ Friedrich Wilhelm Joseph von Schelling, Op.Cit., 1989, p. 17.
} 
E também a seguinte afirmação na introdução de Ideias para uma filosofia da Natureza, de 1802:

O que a filosofia é como tal não pode ser respondido imediatamente. Caso fosse tão fácil concordar com um conceito definitivo de filosofia, seria preciso apenas analisar esse conceito para se ver de posse de um conceito de filosofia de validade universal. O ponto é: filosofia não é algo de que nossa mente, sem sua própria intervenção, é dotada originalmente e por natureza. Filosofia é sobremaneira uma obra da liberdade. Ela é para cada qual apenas aquilo que ele fez dela; e por isso a ideia de uma filosofia é apenas o resultado da filosofia ela mesma; uma filosofia universalmente válida, porém, é um vão fruto da imaginação. ${ }^{10}$

A busca por um sistema filosófico universalmente válido seria, para Schelling, consequência de uma espécie de doença do espírito (Geisteskrankheit) que faz com que um filósofo encontre mais realidade no mundo da abstração do que na experiência. Schelling acusa a mera reflexão (Die bloße Reflexion) de matar as raízes da vida espiritual e preencher o mundo intelectual com quimeras, tornando a cisão entre homem e mundo permanente, e conferindo às criações de nossa mente uma realidade independente da nossa própria.

Uma vez que esse esquema é aceito como verdadeiro, concebe-se igualmente o sistema como independente em si, e esquece-se do fato de que o

\footnotetext{
10 “Was Philosophie überhaupt sey, läßt sich nicht so unmittelbar beantworten. Wäre es so leicht, über einen bestimmten Begriff von Philosophie übereinzukommen, so brauchte man nur diesen Begriff zu analysiren, um sich sogleich im Besitz einer allgemeingültigen Philosophie zu sehen. Die Sache ist diese. Philosophie ist nicht etwas, was unserm Geiste ohne sein Zuthun, ursprünglich und von Natur beiwohnt. Sie ist durchaus ein Werk der Freiheit. Sie ist jedem nur das, wozu er sie selbst gemacht hat; und darum ist auch die Idee von Philosophie nur das Resultat der Philosophie selbst, eine allgemeingültige Philosophie aber ein ruhmloses Hirngespinnst." Friedrich Wilhelm Joseph von Schelling, Ideen zu einer Philosophie der Natur, 1995, p. 249 [SW I/2, 11], tradução nossa.
} 
sistema é a criação de alguém. Schelling fala sobre essa patologia em suas palestras de Stuttgart de 1810, quando ele observa que a afirmação por um pensador de que sua própria criação é universalmente válida é "a mais limitada", se não francamente "escolástica (Schulsystem)". Segundo Bruce Matthews, em seu prefácio à Fundamentação da Filosofia Positiva,

Porque a filosofia é sempre um trabalho criativo de liberdade, Schelling afirma que "os sistemas filosóficos são simplesmente as obras de seus criadores", que, em um sentido importante, são realmente só comparáveis aos "Romances históricos (por exemplo, o sistema de Leibniz)" (I / 7, 421). Os problemas surgem, é claro, quando os autores de tais sistemas esquecem a sua própria liberdade como criadores e confundem suas narrativas criativas com obras de não ficção. E é nesse sentido que, a partir de 1827, Schelling começou a chamar o sistema de Hegel de ficção, porque este último acreditava que ele tinha completado um sistema cujo método e verdade eram universalmente válidos por si mesmos. ${ }^{11}$

O espírito da filosofia moderna perseguia a sistematização e a formalidade, e, utilizando o método crítico, seus resultados são eminentemente negativos. Schelling acusa seus antigos colaboradores, Fichte e Hegel, de terem se recusado a reconhecer a força e a vitalidade do positivo. As formas de conhecimento quantificadoras que se tornaram o objetivo da modernidade - e quantidade aqui não se confundem com o número, mas sim com a redução da

\footnotetext{
11 "Since philosophy is always a creative work of freedom, Schelling argues that 'philosophical systems are simply the works of their creators', which, in an important sense, are really only comparable to 'historical novels (for example, Leibniz's system)' (I/7, 421). Problems arise, of course, when the authors of such systems forget their own freedom as creators and mistake their creative narratives for works of nonfiction. And it is in this sense that, beginning in 1827, Schelling took to calling Hegel's system a fiction because the latter believed he had completed a system whose method and truth were universally valid by themselves." Bruce Matthews, “Translator's Introduction”, 2007, p. 4, tradução nossa.
} 
realidade às categorias possíveis de sua determinação - promoveram necessariamente a separação da intuição sensível de sua reflexão articulada nos conceitos universais das ciências naturais. Esta separação acaba por privar as necessidades do espírito humano de uma unidade possível e de sentido para a existência.

A crítica de Schelling, articulada em torno de sua ideia de filosofia negativa e filosofia positiva, enraíza-se no que poderia ser tomado como a força motriz de toda sua obra, qual seja, o ímpeto de explicitar a identidade de ser e pensar. Esse ímpeto reconhece ao bruto fato do ser, no entanto, uma positividade própria que não advém do fato de ser pensado, ou seja, posto pelo pensamento. $O$ objetivo da filosofia negativa, segundo Schelling, é o propósito da razão de apreender o "ser ele mesmo em sua pureza, sendo exaltado além de toda dúvida"12, o que a razão seria capaz de alcançar à medida que elimina aquilo que é contingente, isto é, toda determinação contingente, liberando o ser do mundo das possibilidades e chegando ao seu cerne necessário. Isto que é necessário, contudo, tendo sido alcançado pelo processo crítico, o qual remove do ser "aquilo que se encontra implícito ou em potência no conceito geral e indeterminado do ser", resulta em um conceito do ser ele mesmo que não é mais que "aquilo que não é o não-ser"13. A filosofia negativa, porque resulta em um conceito do ser inteiramente negativo, não é capaz de gerar mais nada, sendo determinada diante daquilo que foi eliminado como o ser meramente aparente. A filosofia negativa não tem o ser senão como o que resta ao fim de um processo negativo, e

\footnotetext{
12 “[...] um zu dem Seyenden selbst in seiner Lauterkeit, zu dem über alle Zweifel erhabenen Seyenden zu gelangen [...]." Friedrich Wilhelm Joseph von Schelling, Einleitung in die Philosophie der Offenbarung oder Begründung der positiven Philosophie, 1858, p. 79, tradução nossa.

13 "[...] denn dieses ist nur das, was nicht - ist und nicht ist [...]" Ibidem, p. 70, tradução nossa.
} 
aquilo que é eliminado, segundo Schelling, o ser efetivamente positivo, ou então, o ser efetivamente sendo, permanece fora do movimento da razão. A filosofia negativa, sozinha, não seria, portanto, capaz de apreender, e certamente não seria capaz de realizar, apenas pela via da razão, da parte teórica da filosofia, a efetiva identidade entre ser e pensar. Gerado apenas pela reflexão mediada, o conceito "ser" não é capaz de demonstrar a efetiva existência da ideia "ser" - do que já chamamos aqui, com certa liberdade retórica, o fato bruto do ser.

O começo do mundo não se encontra na reflexão. Para Schelling, o material positivo indiferenciado de nosso conhecimento é o fato incondicionado, e por isso, absoluto, da existência, isto é, "de algo é". "Como tal conhecimento é possível não pode ser compreendido enquanto todo conhecimento é visto como subjetivo, como se não pertencesse ao mundo"14. A existência - e com isso minha existência como sujeito cognoscente - é inteiramente enraizada no mundo existente, na positividade da natureza, de tal modo que nosso pensar é um produto natural do mundo.

O idealismo conseguiu isso: somente o mundo alemão tem tal experiência, que seria difícil para alguém de posse dessa explicação ser ouvido. Essa maneira de se livrar do impasse também é contrária ao contrato que existe entre a filosofia e a não-filosofia, a saber, que cabe ao filósofo explicar o mundo; mas agora, ele facilita a tarefa para si se ele corta uma parte considerável da explicação; como se um cirurgião que prometesse curar minha perna quisesse fazer isso amputando-a. Assim, a filosofia deve com

\footnotetext{
14 "Wie eine solche Erkenntniß möglich, ist nicht einzusehen, solange alle Erkenntniß als eine subjektive betrachtet wird, gleichsam als gehörte nicht auch sie zur Welt".

Friedrich Wilhelm Joseph von Schelling, System der gesammten Philosophie und der Naturphilosophie insbesondere, 1860, p. 144 [SW I/6, p. 144], tradução nossa.
} 
seus pressupostos começar por atribuir ser também à parte na natureza que não é cognoscente $[. ..] .{ }^{15}$

O desafio de Schelling é explicar por que a condição de todo conhecimento não pode ela mesma ser conhecida. É este o desafio de suas Preleções sobre a fundação da filosofia positiva, embora essa crítica ganhe formulação primeiro na época da redação da obra inacabada As Idades do Mundo, na década de 1810, como contraponto à filosofia negativa do idealismo alemão. Inclui-se aí sua própria filosofia da juventude, e, de fato, toda a sua filosofia até o fim do período da chamada "filosofia da identidade", uma ruptura marcada em especial pelo Tratado sobre a liberdade humana. Nessa obra, a questão da finitude será tratada não no horizonte da infinitude, no esquema e no limite da eternidade, porém na forma própria e positiva da temporalidade finita. Segundo Jean-François Courtine,

Para dizer a verdade, se tivéssemos que procurar nas pesquisas de $1809 \mathrm{o}$ primeiro início de um novo pensamento sobre a temporalidade, em uma ruptura franca com as determinações da filosofia da identidade, que fizeram da temporalidade uma categoria de finitude, radicalmente estranha ao eterno Absoluto e fora do tempo, indubitavelmente devemos recorrer muito menos à famosa dissociação do "fundo" e da "existência" do que à ideia do Deus em devir, do Absoluto entendido como vida, força,

15 "Dieses hat der Idealism ausgefürht, allein die deutsch Welt hat schon eine solche Erfahrung daß schwerlich noch einer mit einer solchen Erklärung Gehör finden würde. Diese Art sich aus der Verlegenheit $\mathrm{zu}$ helfen ist auch gegen den Vertrag, der zwischen Philosophie und Nichtphilosophie besteht, daß nemlich der Philosoph die Welt erkläre; nun macht er sichs aber mit der Eklärung sehr leicht wenn er einen beträchtlichen Theil derselben wegschneidet; grade wie wenn ein Chirurg der er mir versprochen ein Bein zu heilen, dies dadurch thun wollte, daß er mir das Bein abnimmt. Also die Philosophie muß mit der Voraussezung anfangen auch dem nichterkennenden Theil in der Nature in Sein zuzusprechen [...]" Friedrich Wilhelm Joseph von Schelling, System der Weltalter: Münchener Vorlesung 1827/28 in einer Nachschrift von Ernst von Lasaulx, 1998, p. 94, tradução nossa. 
antagonismo e jogo de forças: unidade móvel e viva de forças opostas (lebendige Einheit von Kräften) que pertence ao amor de deixar ser na própria tensão em que elas encontram sua coesão. ${ }^{16}$

Para Schelling, localizar o começo da filosofia na existência fática significa abandonar o sujeito autoconsciente como o âmbito fundamental, no qual o posicionamento do Eu deveria coincidir com a apreensão da totalidade do ser, em favor de uma compreensão da dívida que a autoconsciência tem para com o caráter "pré-predicativo" da existência. A primeira coisa que pode ser pensada, de acordo com Schelling, é a negatividade, no sentido do Seynkönnendes ou “poder-ser", quer dizer, aquilo que permite toda determinação, mas que, porém, não é determinável em si mesmo. O começo do pensamento - o que Schelling entende como a primeira potência - não é apenas aquilo que permite o surgimento do si mesmo para a consciência como consciência do Ser (que caracteriza a "ontonomia" da consciência), mas aquilo que experimenta a si mesmo, primeiro e na maior parte das vezes, como consciência da divindade (a "teonomia" da consciência). A experiência primordial do sagrado, através da qual o ente finito pronuncia a si mesmo, não simplesmente como o "Eu" egoísta, porém como um habitante do mundo, informa a compreensão da existência fática como "voltada para o ser" (Seinsbezogen), não como modelo precursor ou

\footnotetext{
16 “À vrais dire, s'il fait chercher dans les Recherches de 1809 le premier amorçage d'une nouvelle pensée de la temporalité, en rupture franche avec les déterminations de la philosophie de l'identité, qui faisait de la temporalité une catégorie de la finitude, radicalement étrangère à l'Absolu éternel et hors temps, c'est sans doute moins vers la célèbre dissociation du "fond" et de l' "existence" qu'il faudrait se tourner, que vers l'idée du dieu en devenir, de l'Absolu appréhendé comme vie, force, antagonisme et jeu des forces: unité mobile et vivante de forces opposées (lebendige Einheit von Kräften) qu'il appartient à l'amour de laisser être dans la tension même où elles trouvent leur cohésion." Jean-François Courtine, Schelling entre temps et éternité: histoire et préhistoire de la conscience, 2012, p. 60, tradução nossa.
} 
alegoria de um esquema categorial, mas como relação ela mesma fundamentalmente significativa. A questão permanece, contudo, como pode a natureza ela mesma - quer dizer, o que não é já autoconsciência - resguardar a possibilidade mesma daquilo que é considerado "espiritual" ou "subjetivo", isto é, a possibilidade da significação ou determinação. Não sem razão, Schelling dedica-se, em sua obra madura, à elaboração, na forma de preleções, de uma "filosofia da Mitologia" e de uma "filosofia da revelação", nas quais a questão da facticidade da existência - ou seja, da positividade prévia ao instante da autoconsciência reflexiva - toma precedência sobre a discussão sobre o método da filosofia, sobre seu caráter sistemático, ou sobre a própria possibilidade de um sistema do conhecimento. Conforme Markus Gabriel,

\begin{abstract}
Para a abordagem da Filosofia da Mitologia, deve-se, portanto, afirmar que Schelling primeiro pensa no homem como consciência. O ser humano ainda não é um Dasein, como mais tarde com Heidegger, também não naturalisticamente como ser vivo (seja ele privilegiado) ou materialistamente como um animal que trabalha, mas idealisticamente determinado a partir da representação. A atitude antropológica básica de Schelling está ligada ao fato de que ele considera principalmente a mitologia como um todo de representações, quer dizer, a pensa idealisticamente como um "contexto de formas". Ele havia feito isso na Filosofia da Arte, demonstrado pelo fato de ter construído o Panteão como o cosmos de ideias na potência da intuição. Para explicar que o homem não representa meramente o mundo, Schelling não usa mais o conceito meramente formal de consciência de Kant. Em vez disso, ele pensa a consciência metafisicamente ontonômica: a consciência está relacionada a si mesma com o fundamento original do todo, o ser absoluto. ${ }^{17}$
\end{abstract}

\footnotetext{
17 "Für den Ansatz der Philosophie der Mythologie ist dennach festzuhalten, daß Schelling den Menschen zunächst als Bewußtsein denkt. Der Mensch wird noch nicht als Dasein, wie später bei Heidegger, noch auch naturalistisch als (sei es auch ausgezeichnetes) Lebewesen oder materialistisch als arbeitendes Tier, sondern idealistisch von der Vorstellung aus bestimmt. Schellings anthropologische Grundannahme hängt damit zusammen, daß er die Mythologie prinzipiell als ein Ganzes von Vorstellungen, d.h. idealistisch als "Gestaltzusammenhang" denkt.
} 
A questão da ontonomia, ou consciência do ser, poderá ser tratada em outras palavras como o problema da possibilidade do conhecimento de que trata Schelling no Sistema do Idealismo Transcendental, no qual o sistema do conhecimento encontra na autoconsciência o princípio exigido para que possa ser de fato um sistema, um princípio único, irredutível e incondicionado. Schelling pretende resolver a contradição inerente ao problema da possibilidade do conhecimento, qual seja: o conhecimento exige a síntese de pensamento e de algo alheio ao pensamento, e por isso, a mera identidade do pensar, ou seja, a mera proposição $\mathrm{Eu}=\mathrm{Eu}$, não pode ser esse princípio. $\mathrm{O}$ conhecimento, no entanto, para que seja verdadeiro, deve se remeter a uma certeza incondicionada, a qual só pode ser dada pela identidade do pensar, o que é, portanto, contraditório. Como poderá ser encontrado um ponto que seja, ao mesmo tempo, sintético e idêntico, sintético e incondicionado?

\begin{abstract}
Aquilo que surge para nós por meio do ato original da intuição intelectual pode ser formulado em uma proposição básica, a qual pode ser chamada de a primeira proposição básica da filosofia. Agora, por meio da intuição intelectual, surge para nós o Eu, na medida em que ele é seu próprio produto, de uma vez produzindo e produzido. Esta identidade entre o Eu como produzindo e o Eu como produzido é expressada na proposição $E u=E u$; porque ela iguala opostos a ele mesmo, esta não é de forma alguma uma proposição idêntica, porém uma sintética. ${ }^{18}$
\end{abstract}

Dies hatte er ja bereits in der Philosophie der Kunst getan, was sich darin zeigte, daß er das Pantheon als den Ideenkosmos in der Potenz der Anschauung konstruierte. Um nun zu erklären, daß der Mensch nicht bloß Welt überhaupt vorstellt, greift Schelling weiterhin nicht mehr auf Kants bloß formalen Bewußtseinsbegriff zurück. Stattdessen denkt er Bewußtsein metaphysisch ontonom: Das Bewußtsein ist an ihm selbst auf den Urgrund des Ganzen, das absolute Sein bezogen." Markus Gabriel, Der Mensch im Mythos, 2006, p. 281, tradução nossa.

18 "Was uns durch den ursprünglichen Akt der intellektuellen Anschauung entsteht, kann in einem Grundsatz ausgedrückt werden, den man ersten Grundsatz der Philosophie nennen kann. - Nun entsteht uns aber durch intellektuelle Anschauung das Ich, insofern es sein eigen Produkt, 
A identidade no pensamento do Eu consigo mesmo, segundo Schelling, alcança esse objetivo à medida que o Eu ele mesmo produz a si mesmo enquanto sujeito e objeto, não no sentido de um "algo", de algo que é pensado no pensamento, ou seja, representado, mas primordialmente como atividade e limitação. O sistema do conhecimento é o retorno ao princípio desde a limitação até sua liberdade original, tornando-se primeiramente para si mesmo, ou seja, conscientemente, o que já era em si mesmo, pura liberdade e atividade. A autoconsciência emerge enquanto ato absoluto. Absoluto significa incondicionado. Significa a simultaneidade do ato enquanto real e ideal, o qual, porém é apresentado na Filosofia sucessivamente: em sua idealidade, o conteúdo e a forma do conhecimento devem ser gerados em um único ato, e o Eu enquanto sujeito-objeto absoluto corresponde, para Schelling, à exigência de pressuposição recíproca que somente justifica o princípio do conhecimento. 0 ato absoluto não produz nada, efetivamente, como um algo, nem mesmo uma ideia ou representação: o ato absoluto produz a síntese absoluta, ou, se podemos dizer retoricamente, produz a própria síntese em absoluto - como se fosse a primeira vez, ou de outra maneira, ainda somente idealmente, demonstrando, pois, a possibilidade do conhecimento.

A afirmação da idealidade da síntese absoluta não será, no entanto, suficiente para Schelling; será preciso encontrar a possibilidade da realidade da síntese entre real e ideal, sujeito e objeto: a realização do projeto filosófico. Para

Producirendes zugleich und Producirtes ist. Diese Identität zwischen dem Ich, insofern es das Producirende ist, und dem Ich als dem Producirten, wird ausgedrückt in dem Satz das Ich = Ich, welcher Satz, da er Entgegengesetzte sich gleich setzt, keineswegs ein identischer, sondern ein synthetischer ist." Friedrich Wilhelm Joseph von Schelling, System des transzendentalen Idealismus, 1995, p. 440 [SW I/3, 372], tradução nossa. 
Schelling, essa realização encontra-se não no discurso filosófico, mas na intuição estética, a qual possibilitaria o acesso à autoconsciência absoluta, ou seja, ao absolutamente idêntico, idealmente projetado na filosofia teórica. A intuição estética deverá corresponder à promessa da intuição intelectual; é na sexta parte do Sistema do Idealismo Transcendental que Schelling, afinal, anuncia a tarefa de sua filosofia da identidade, a qual começa a levar a cabo com o projeto da filosofia da arte, cujo mais poderoso instrumento parece ser a construção de uma linguagem simbólica capaz de dar conta daquilo que a reflexão deixa de fora.

A construção simbólica da linguagem, ou em última instância, da síntese enquanto construção do universo, e não somente na forma das proposições da filosofia teórica, parece promover uma transformação especulativa decisiva no pensamento de Schelling. Essa transformação não se dá somente no que diz respeito à filosofia da identidade, ou, em particular, à filosofia da arte, mas permitirá à Schelling, ao longo de sua obra, perseguir "a natureza extra-lógica da existência", sem abandonar o pendor sistemático de sua filosofia, seja em As Idades do Mundo, na Filosofia da Mitologia ou na Filosofia da Revelação, em que Schelling busca a identidade entre o princípio consciente e o obscuro princípio inconsciente em nós - a "Mitwissenschaft da criação".

\section{Referências}

BOWIE, Andrew. Schelling and Modern European Philosophy: An Introduction. London; New York: Routledge, 1993. 
COURTINE, Jean-François. Schelling entre temps et éternité: histoire et préhistoire de la conscience. Paris: Vrin, 2012.

GABRIEL, Markus. Der Mensch im Mythos: Untersuchungen über Ontotheologie, Anthropologie und Selbstbewusstseinsgeschichte in Schellings Philosophie der Mythologie. Berlin; New York: Walter de Gruyter, 2006.

KANT, Immanuel. Crítica da razão pura. Traduzido por Manuela Pinto dos Santos e Alexandre Fradique Morujão. Lisboa: Serviço de Educação, Fundação Calouste Gulbenkian, 1994.

MORUJÃO, Carlos. Introdução. In: SCHELLING, Friedrich Wilhelm Joseph von. Investigações filosóficas sobre a essência da liberdade humana e os assuntos com ela relacionados. Traduzido por Carlos Morujão. Lisboa: Ed. 70, 1993.

SCHELLING, Friedrich Wilhelm Joseph von. Cartas filosóficas sobre o dogmatismo e o criticismo. In: Obras escolhidas. 3. ed. Traduzido por Rubens Rodrigues Torres Filho. São Paulo: Nova Cultural, 1989.

SCHELLING, Friedrich Wilhelm Joseph von. Einleitung in die Philosophie der Offenbarung oder Begründung der positiven Philosophie. Sämtliche Werke, II Abtheilung, Dritter Band. Stuttgart: Cotta, 1858.

SCHELLING, Friedrich Wilhelm Joseph von. Grundlegung der positiven Philosophie: Münchener Vorlesung WS 1832/33 und SS 1833. Turin: Bottega D’Erasmo, 1972.

SCHELLING, Friedrich Wilhelm Joseph von. Ideen zu einer Philosophie der Natur. In: Ausgewählte Schriften I. 1794-1800. Frankfurt a. M.: Suhrkamp, 1995. 
SCHELLING, Friedrich Wilhelm Joseph von. System der gesammten Philosophie und der Naturphilosophie insbesondere. Sämtliche Werke, I Abtheilung, Sechster Band. Stuttgart: Cotta, 1860.

SCHELLING, Friedrich Wilhelm Joseph von. System des transzendentalen Idealismus. In: Ausgewählte Schriften I. 1794-1800. Frankfurt a. M.: Suhrkamp, 1995.

SCHELLING, Friedrich Wilhelm Joseph von. System der Weltalter: Münchener Vorlesung 1827/28 in einer Nachschrift von Ernst von Lasaulx. Organizado por Siegbert Peetz e Ernst von Lasaulx. Aufl. Frankfurt am Main: Klostermann, 1998.

MATTHEWS, Bruce. Translator's Introduction. In: SCHELLING, Friedrich Wilhelm Joseph von. The Grounding of Positive Philosophy: The Berlin Lectures. Traduzido por Bruce Matthews. Albany: State University of New York Press, 2007.

SCRIBNER, F. Scott. A Blasphemous Monologue. In: WIRTH, Jason M. (Org.) Schelling now: contemporary readings. United States: Indiana University Press, 2004.

\section{Referência para citação deste artigo}

FÉLIX, Wagner. Filosofia negativa, filosofia positiva: a crítica de Schelling ao idealismo. Revista PHILIA | Filosofia, Literatura \& Arte, Porto Alegre, volume 2, número 1, p. 590 - 613, junho de 2020. 